\title{
El desarrollo humano desde la biojurídica colombiana para los habitantes de la calle drogodependientes"
}

\section{Human Development From Colombian Biojustics For Drug-Addicted Street Dwellers}

\author{
Edwin Secergio Trujillo Florián Ph.D.'
}

Copyright: $\odot 2019$

Revista Internacional de Cooperación y Desarrollo.

Esta revista proporciona acceso abierto a todos sus contenidos bajo los términos de la licencia creative commons AtribuciónNoComercial-SinDerivar 4.0 Internacional (CC BY-NC-ND 4.0)

Tipo de artículo: artículo de revisión

Recibido: julio de 2019

Revisado: agosto de 2019

Aceptado: septiembre de 2019

\section{Autor}

1 El autor es graduado del programa de Doctorado en Bioética, Facultad de Educación y Humanidades, Universidad Militar Nueva Granada, Bogotá, Colombia. Director de tesis: Nelson Molina Ramírez Ph.D.

ORCID https:// orcid org/0000-0003-2203-7704

Correo electrónico: edwin.trujillo@unimilitar.edu.co

\section{Cómo citar:}

Trujillo Florian, E. (2020). El Desarrollo humano desde la biojurídica colombiana para los habitantes de la calle drogodependientes. Revista Internacional de Cooperación y Desarrollo. 6(2). 33-49

DOI $10.21500 / 23825014.4095$

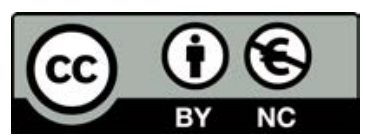

\section{Resumen}

La biojurídica permite preguntarse: ¿Cómo se incentiva el desarroIlo humano en la jurisprudencia frente a los Objetivos de Desarrollo Sostenible (ODS) 1 y 3 en relación con el consumo de estupefacientes y el habitante de la calle? El objetivo es determinar el diagnóstico del desarrollo humano para el habitante de la calle drogodependiente y analizar su sentido de vida conforme a las tendencias ius filosóficas que deberían incluirse en las sentencias. Se proponen algunas líneas de pensamiento filosófico aristotélico, el enfoque corresponde a una investigación documental interpretativa y el proceso de revisión y reflexión se sustenta en la información obtenida en textos y artículos de revistas indexadas. Es importante incorporar el lenguaje de la ética y la política en aspectos como la felicidad, la justicia, la virtud moral, cívica y política, y la educación de los sentimientos en la jurisprudencia.

Palabras clave: dignidad y adicción; jurisprudencia y consumo de estupefacientes; libertad y drogodependencia.

\section{Abstract}

The biojuridic allows us to ask ourselves: How is human development promoted in jurisprudence against the objectives of sustainable development (SDG) 1 and 3 in relation to the consumption of narcotics and the inhabitant of the street? The objective is to determine the diagnosis of human development for the inhabitant of the drug-addicted street and analyze their sense of life according to the philosophical trends that should be included in the sentences. Some lines of Aristotelian philosophical thought are proposed, through interpretative documentary research and the reflective process is based on the information obtained and analyzed in texts and articles of indexed journals, with critical analysis. It is important to incorporate the language of ethics and politics in aspects such as happiness, justice, moral, civic and political virtue, and the education of feelings in jurisprudence.

Keywords: dignity and addiction; jurisprudence and consumption of narcotics; freedom and drug addiction. 


\section{Introducción}

La Dignidad Humana como categoría de humanización y desarrollo de la persona fija que estos comprendan en su integridad derechos y deberes, y no exclusivamente de los primeros porque el hombre es «ex-sistencia es a diferencia fundamental de toda existentia o existence, el morar extático en la proximidad del ser. Es la guarda, es decir, el cuidado del ser» (Heidegger, M.\& Girardot, R., 1970, pp.13-25). Lo anterior quiere decir que el hombre debe cuidar y guardar de su propio ser por medio de su existencia. Caos (2016), en referencia a Heidegger, afirma que todo existe y todo a la vez es nada; empero, lo que es corpóreo y eminentemente humano se diferencia de la cosa, porque el hombre tiene la facultad de preguntarse por sí mismo acerca de su existencia. El problema surge, según Lévinas (1996), cuando el ser humano apoyado por factores externos (como la ley) se establece desde un sentido óntico o banal, y no ontológico sin comprender su propio ser, por tanto debe ser óntico-ontológico, porque el hombre pertenece a su esencia existir, para luego entender que debe relacionarse con el otro.

El objetivo es determinar el diagnóstico del desarrollo humano para el habitante de la calle drogodependiente y analizar su sentido de vida conforme a las tendencias ius filosóficas que deberían incluirse en las sentencias. El reconocimiento de la dignidad, en el sistema jurídico colombiano, ha hecho que a los habitantes de la calle no se les exija en deberes como al ciudadano común. Es cierto e indiscutible que gocen de todas las garantías que se le puedan otorgar a los ciudadanos, tal como se pregona en las sentencias C-221 de 1994 y T-043 de 2015: en la primera se le reconocen derechos a los drogodependientes a optar por una enfermedad de la cual no desean ser curados y en la segunda, la Corte Constitucional le ordenó al ejecutivo adoptar políticas públicas, para garantizar que la Ley 1641 de 2013
(Ley de los habitantes de la calle) se aplique; empero, el afán por exponer las garantías o los derechos de estas personas ha hecho que se piense en ellos más como sujetos en una condición de superioridad en derechos, pero en inferioridad en deberes sin tener un enfoque en su desarrollo como personas.

La jurisprudencia constitucional ha sustentado sus tesis en un modelo de Estado social de derecho y la defensa de la libertad individual en condiciones de igualdad material. El mandato es reconocer las garantías a los habitantes de la calle, mediante la evaluación de los criterios jurisprudenciales de mendicidad, drogodependencia y marginalización como fundamentos para el libre desarrollo de la personalidad conforme a su plan de vida. Según el utilitarismo liberal, las condiciones señaladas no vienen a ser consecuencias de la indignidad del ser humano, sino que se convierten en estados que se ajustan al plan de vida del habitante de la calle siempre y cuando no afecte los derechos de los demás. El problema es que la Corte Constitucional, ${ }^{1}$ de manera evidente, le otorga a la dignidad un contenido nihilista ya que hace que el hombre carezca de propósito y manifieste su desorden como un estilo de vida.

La interpretación de la «libertad»por parte de la Corte Constitucional, que busca dignificar el fenómeno de la mendicidad, otorga el valor de «opción de vida» para ser ejercida de manera autónoma y personal. Esta posibilidad es motivo suficiente para escudriñar y describir el concepto de dignidad, según los postulados filosóficos de Aristóteles y de algunos pensadores que tienen posiciones acordes a esta filosofía como Heidegger en El ser ontológico, Lévinas con la ética y la relación con el otro, Arendt y La condición humana, Nussbaum y el nuevo consenso, entre otros. Los autores anteriores fundamentan la posibilidad de entender la Dignidad como un principio que exis-

\footnotetext{
${ }^{1}$ Ver sentencia T-043 de 2015
} 
te en el ser humano, pero que se manifiesta en el goce de los derechos y en el ejercicio de los deberes, como fin, entonces, el Estado social de derecho debe insistir en los modelos de intervención terapéutica para los drogodependientes sin «cosificar» al ser humano ya que en últimas lo que se busca es su curación y su resocialización, lo cual permita su desarrollo conforme los ODS, en especial los objetivos 1 y 3 . $^{2}$

Realizada la discusión y descripción de los razonamientos filosóficos, estos se confrontarán con los argumentos expuestos en las sentencias de la Corte Constitucional la cual ha interpretado erróneamente el concepto de Dignidad; en dichas sentencias prima la autonomía como principio bioético, socavando la beneficiencia, la no maleficiencia y la justicia. La Sentencia T-043 hace énfasis en los estudios sobre neurociencia y apoyo médico al adicto; sin embargo, no muestra que el fin de la filosofía en bioética es relevante y crucial. Los resultados de las investigaciones en neurociencia han sido enfáticos en constatar que la drogadicción al ser una enfermedad también es un fenómeno problemático biopsicosocial (Engle, 1977, citado por Cruz-Bermúdez, 2013).

La ciencia, según Everitt \& Robbins, (2005); Hyman, Malenka \& Nestler, (2006) en su búsqueda por entender los cambios neurobiológicos en el paciente drogodependiente ha llegado a la conclusión que el sistema dopaminérgico es el punto central en el desarrollo de la adicción con la generación de estímulos que se presentan al establecer hábitos que producen placer como la comida, el sexo, los amigos, la euforia, entre otros. Dar respuesta a este problema permitirá detectar el distorsionado discurso de la Corte Constitucional y los desacuerdos en relación con el principio bioético de la autonomía y su aplicación que vulnera los demás principios clásicos de beneficen-

${ }^{2}$ Los Objetivos de Desarrollo Sostenible 1 y 3 se refieren a poner fin a la pobreza en todas sus formas y garantizar una vida sana y promover el bienestar para todos. cia, no maleficencia y justicia, y provoca rechazo al pobre.

El artículo tiene como fundamento la investigación documental interpretativa debido a que la base del proceso reflexivo se sustenta en la información obtenida y analizada, mediante la consulta bibliográfica de textos y artículos de revistas indexadas de contenido bioético y filosófico que sustentan una biojurídica aplicable en términos de dignidad, para los habitantes de la calle drogodependientes y se hace una aplicación del análisis crítico del discurso.

I. La Biojurídica, la Dignidad y el propósito del ser humano

En última instancia, vivir significa asumir la responsabilidad de encontrar la respuesta correcta a los problemas que ello plantea y cumplir las tareas que la vida le asigna continuamente a cada individuo Frankl, V. 1991

La biojurídica tiene la función de reflexionar de manera crítica el derecho en todas sus esferas (constitución política, leyes, jurisprudencia, resoluciones, entre otros), no a partir de las normas en su estructura material, sino en su estructura ontológica. Su función va ligada a la filosofía del derecho con enfoque en la Dignidad Humana, la Justicia y los Derechos Humanos. Miralles (2007) afirma que la biojurídica tiene un reto, incluir los derechos bioéticos en el plano de los Derechos Humanos para que el ser humano pueda ejercerlos conforme a su razón, su humanidad y su relación con el otro.

El punto de encuentro entre derecho-bioética se denomina biojurídica, la cual fundamenta y establece la pertinencia de las normas jurídicas legales o jurisprudenciales «para adecuarlas a los valores de la bioética» (Gutiérrez \& Vila - Coro, 2007, p.53). Un ejemplo podría ser una política gubernamental de atención integral en sa- 
lud con sistema de salud al servicio de la gente (Minsalud, 2016), la cual ha buscado incentivar el autocuidado del individuo, no solo su salud, sino también la de su familia, la comunidad y el medioambiente, como lo afirma la OMS (2004).

Miralles (2007) considera que la expresión biojurídica tiene relación única y exclusivamente en el ámbito de la filosofía del derecho, y no con esquema positivo de las normas civiles, penales y su legislación; por lo tanto, se considera que la biojurídica se manifiesta en toda clase de normas expedidas sea por el Cobierno o ejecutivo (decretos, resoluciones, acuerdos), el legislativo (Leyes) o la rama judicial (jurisprudencia, autos) que buscan regular las relaciones entre los seres humanos y con la vida, y en este punto se analiza su contenido moral, de principios y su estructura filosófica. Pueden existir contrariedades entre las ramas del poder público, verbigracia, el Cobierno expide decretos que prohíben el porte de la dosis mínima de estupefacientes y las altas cortes expiden jurisprudencia en contravía con el decreto, $y$ fundamentan sus posturas en la prelación de la autonomía del individuo con lo cual se puede afectar su salud al consumir estupefacientes.

Los ejemplos de biojurídica son variados: La jurisprudencia de la Corte Constitucional que garantiza el derecho de acceso a la salud para los drogodependientes habitantes de la calle, también se ha expedido una ley que sugiere políticas públicas en favor de los habitantes de la calle; el Código Penal prohíbe tráfico y el porte de estupefacientes, así como el acuerdo de paz entre el Cobierno Nacional y las FARC trató el narcotráfico en el punto 4 y la Constitución Política en su artículo 49 regula lo pertinente al acceso a la salud a la población, el deber de autocuidado y el de garantizar la salud de su comunidad.

Gutiérrez \& Vila - Coro (2007) consideran que la biojurídica tiene como fin la fun- damentación y la importancia de las normas para que esta sea apta a los valores de la bioética; por lo tanto, estudia el contenido moral y ético de las leyes. La biojurídica hace que la cultura, las leyes normativas sociales, morales, bioéticas y jurídicas penales regulen las conductas de los habitantes. Se crean deberes, leyes y normas estipuladas en el ámbito del derecho, cuya misión es garantizar el respeto por los derechos de cada persona y de un conglomerado por conductas que puedan lastimar bienes jurídicos tutelados en procura de un adecuado desarrollo de la vida social. La moral es parte fundamental de las normas jurídicas y debe hacer parte del derecho porque:

Son sistemas normativos diferentes entre sí que aunque proyectándose sobre la misma realidad humana lo hacen desde presupuestos y teleologías distintos. Sin embargo, esto no debe llevar a la afirmación de la separación entre ambos, sino a la necesaria complementariedad (Amor, 2005, p.72).

Amor (2005) considera que la moral debe impregnar todas las esferas del derecho, sea en la legalización, despenalización o prohibición de diferentes acciones u omisiones, y no caer en argumentos propios de la teoría pura del derecho kelseniano que niega de manera radical la relación del derecho con la moral. Miralles (2007) cree que la biojurídica aborda diversos problemas referidos al problema conceptual, a la dimensión axiológica, y por último a la intersección entre el bioderecho y la realidad social; por lo tanto, se hace necesario abordar cada uno de ellos en forma breve.

El propósito (deseo, proyección, objetivo o aspiración) es una necesidad universal inmersa en todo ser humano y permite su desarrollo, puesto que sin esto no se puede llegar al bien más preciado por todos, la felicidad. Existe una conexión entre felicidad y propósito, porque este permite superar aquellas dificultades que presenta la vida 
como la pérdida de un ser querido, superar las rupturas amorosas, las adicciones a las drogas o el escape de la pobreza extrema. Aristóteles consideraba que el universo está compuesto de propósito; por tanto, todas las cosas desarrollan un impulso propio, aun así es preciso señalar que para el autor griego el universo y todo lo que está en él siguen una directiva primerísima. Cualquier extravío de esta va en contra de la realidad y la verdad, porque la teleología se ocupa del orden, la estabilidad y el logro. Esta idea también fue acogida por Santo Tomás (D. A. 2001, q.2, a.3), para quien el Universo tenía un motor esencial que se encargaba de ordenar y mover todo.

Aristóteles (1970) afirma que el propósito del ser humano es la felicidad o la llamada eudemonía que significa el «buen ánimo»; por lo tanto, la felicidad en el hombre se puede medir por su vida ordenada, con buenos hábitos, mente sana y disposición para la virtud que lo llevan a una felicidad verdadera. $Y$ es por esto, que el hombre combate día a día con este fin, porque lo esencial de la ética es el bien relacionado con la felicidad; por tanto, quien sea feliz y goce de hacer el bien se le llama «hombre virtuoso» porque este tiene la costumbre del bien hacer. Al ser el hombre Politikon viene a ser social y necesita de los otros para alcanzar la felicidad completa, por lo que no se acepta que la exclusión genere en algún sentido felicidad, según un punto de vista ético.

Todos los seres humanos buscan ser felices, o alcanzar la satisfacción personal de alguna forma. Ferraris (2000) y Oriol-Bosch (2012) consideran que carecer de objetivos y vivir una vida desordenada hace parte de la filosofía nihilista, porque la forma recomendada por la psicología para superar cualquier adversidad en la vida es la resiliencia la cual se expresa como esa posibilidad de adaptación del individuo frente a los retos y a las amenazas viviendo para desa- rrollarse positivamente a fin de superarse; sin embargo, la sociedad está creando cada día hombres débiles en carácter, sin propósito, que ante cualquier amenaza de tensión buscarán refugio en cualquier situación que aligere las cargas de forma momentánea. Este es el caso de la drogadicción o la búsqueda del dinero fácil, mediante la mendicidad como forma de vida.

El individuo puede buscar el bien en un sentido opuesto al criterio ontológico y ordenado, según Aristóteles, y es el criterio que tiene Parsons, T. (1970) en entropía evolutiva y transformadora social, según la teoría del conflicto trata de establecer cómo funciona una sociedad, mediante macrosistemas e interpretación total del consenso o la vida en comunidad. Es la entropía evolutiva la que permite que los hombres puedan encontrar su camino sin necesidad de tener deidades inspiradoras, sino que comprenden que el universo sigue su rumbo y cada hombre se adapta para cumplir su función o rol social en medio de un desorden o un caos inevitable. El hombre, independientemente de la forma como busque la felicidad, es importante para el otro. El sentido de la vida empieza y termina con la manera como el ser habla de su propia existencia, su cultura, sus mitos y su propia existencia.

El sentido y el propósito, según un punto de vista naturalista, para Carroll (2017) no son parte de la arquitectura del universo, pero si nacen como formas de expresar el entorno del ser humano; por tanto, ni los materialistas, ni los nihilistas pueden negar que los propósitos existan para suministrar la felicidad. La conducta guiada por un objetivo contiene una ventaja evolutiva, según Falk (2000) el ser humano como especie se beneficia de la creencia de este en su proceso, ya que el propósito surge del deseo de subsistencia, en un universo variante. El sentido de existencia es una reacción de la indiferencia del universo hacia el ser lo que permite crear cuentos, mitos, historias, tra- 
diciones, culturas, leyes y sistemas que dan orden y sentido al humano; por lo tanto, para Blumenberg (2003) esto se entiende porque el propósito se origina en la sabiduría popular la cual sirve como directiva, para que el mundo exista.

Un sistema caótico, entrópico e indiferente ofrece una justificación fuerte y atractiva para que el hombre viva con satisfacción y en una Justicia al estilo de Sen (2010), porque permite que se ponga la atención en el mundo, enseña que esta vida importa y que el hombre viene a ser el único responsable de ella. Sentimientos como el amor, la amistad y el perdón existen, porque benefician al hombre y su entorno, mientras que circunstancias como la guerra, los homicidios o el narcotráfico se hallan porque se han auto-infligido por el ser humano. Las malas conductas son producto de personas con un propósito diferente al de hacer el bien. En términos de placer, este tiene que regirse por la actividad característica de su vocación, mientras que el hombre perverso siempre buscará placer en lo que no es un bien, y eso no es felicidad, «el arte solo requiere conocimiento, pero la virtud requiere elección racional y ejercicio constante» (Aristóteles, 1970, p.123).

Los propósitos, que establece el ser humano, vienen a ser cuerpos fantasmas según Blumenberg, (2003); las conmemoraciones y recuerdos de personas, sitios, cosas y eventos que se luchan por recordar el sentido de existencia del hombre indica la no permanencia y durabilidad de este en el mundo. Cada cosa que se hace, cada tarea o actividad es un recordatorio de algo que es y que será. El propósito tiene que ver con el sacrificio, para lograr finales felices $y$ esperar una cosa: el final. Aunque la entropía exige que las partículas se cohesionen para transformarse en otras y el universo no razone sobre los propósitos del hombre, es necesario plantear que la sola reflexión sobre el sentido de la vida ya tiene un valor constitutivo, es decir vale por sí mismo.
El problema surge con la interpretación de la «felicidad», la cual se ha relacionado con los principios de un Estado liberal con primacía en la autonomía, la libertad del ser (nadie por él). La jurisprudencia permite la satisfacción de los intereses particulares en razón a unos derechos personalísimos que no deberían interesarle a nadie más sino a quien los posee. Las sentencias C-221 de 1994, C-491 de 2012, el radicado 41760 de 2016, entre otras, son un caso de ejemplo, porque afirman que este comportamiento se «encuentra en la libre determinación y en la dignidad de la persona (autónoma para elegir su propio destino)» (Corte Constitucional, 1994). Esta posición contraría los resultados en salud pública obtenidos a lo largo de estos últimos años (UNODC, 2016) en los cuales Colombia ocupa el segundo lugar (en el mundo) en número de personas que tuvo que acudir a un servicio de urgencias médicas a consecuencia del consumo de marihuana. El ser humano se deshonra a causa de una adicción permisiva.

II. La condición de los drogodependientes habitantes de la calle - el discurso jurisprudencial y el desarrollo humano El ser humano tiene un propósito propio, además, cada persona es diferente e igual en aspectos como la acción y el discurso; es decir, Arendt (1996) al establecer que los hombres están en un plano de igualdad jurídica se pueden planear y preparar conforme a sus necesidades, empero, como son diferentes, es necesario establecer tipos de discurso y acciones. El flagelo del consumo de las drogas implica plantear un tipo de discurso igualitario frente a las consecuencias sociales y en la salud que se presentan en los drogodependientes desde distintas ópticas. El derecho se puede utilizar como mecanismo de persuasión y de prevención para las generaciones futuras en pro del desarrollo humano. El hombre, según Lévinas (1996), por medio de los actos puede inser- 
tarse en el mundo ( $y$ no necesariamente estas acciones van acompañadas de necesidad o utilidad) y esto corresponde a su libertad, que es un valor inalienable que nace con el hombre y la iniciativa de socializar con otras personas y de reconocer al otro.

El hombre puede realizar acciones por sí mismo, y según Arendt (2007) por esta razón se espera de él cualquier cosa, sea buena o sea mala y sus acciones deben estar verificadas y controladas por leyes creadas por hombres mayores que han podido desarrollar procesos de madurez y buena vida. La existencia del hombre trae al mundo algo novedoso (por lo diferente que se es respecto de otros), pero con esto debe aprender a desarrollarse como ser único pero diferente entre iguales, y en esto la jurisprudencia colombiana se ha equivocado al darle prioridad a la autonomía sin pensar en las consecuencias del drogodependiente en su comportamiento para con los demás (hacia el otro) y en el daño que se hace a sí mismo (no maleficiencia).

El antropocentrismo considera al ser humano individual por excelencia, $y$ con esto se niega la capacidad de este para actuar y para asociarse con otros como medio eficaz de supervivencia, para Lévinas (1977) sin el otro no se podría vivir, por lo que la ética no se basa en el ser, sino en la relación, un yo abierto. Por lo tanto, vale la pena indagar si la capacidad que tiene el ser humano de disfrutar de un estupefaciente viene a ser un factor que demuestra ante los demás su derecho al libre desarrollo de la personalidad. El consumidor no afecta la salud de los demás, sino la de él mismo, pero los resultados sociales de adicción y de enfermedad pública dan muestra que el adicto se está des-socializando a tal punto, que su aislamiento es un factor dramático para la sociedad, y se origina la posibilidad de ser en el futuro un habitante de la calle, lo que genera más pobreza.
Existen asociaciones que defienden el consumo de estupefacientes frente a cualquier acción que tome el Cobierno Nacional, por ejemplo con la expedición del Decreto 1844 de 2018, por lo tanto, son personas con problemas de salud y de conducta (por la dependencia) que niegan su adicción ya que la Corte Constitucional y la Corte Suprema de Justicia les ha otorgado el derecho sin medir las consecuencias, con lo cual se afecta el principio de beneficiencia en materia bioética. Arendt (2007) afirma que debe existir una consonancia entre el discurso y la acción para que las personas entiendan que son iguales entre sí, pero diferentes entre ellos para que pueda existir un marco de convivencia entre todos; la libertad del ser humano va ligada a su acción, pero el discurso debe ser para beneficio propio y de los demás como presupuesto de revelación u ocultamiento.

El desarrollo del ser humano permite su revelación frente a los demás, porque sus buenas o malas obras van en pro o en contra de los otros, y la sana lógica muestra que este se esconde, cuando sus actos perjudican a cierto conglomerado. El criminal se marginaliza para que no sea descubierto, el ladrón se esconde para no ser atrapado, esto también se presentaba con los consumidores de drogas, pero hoy, y gracias a la jurisprudencia los adictos desean publicitar su consumo como muestra de orgullo y logro adquirido, sin considerar sus consecuencias, así lo exponen Royo-Isach, Magrané, Blancafort \& Ferrer (2004). Las consecuencias del desconocimiento del futuro le impide al ser humano consumidor ver la posible llegada de una adicción en la que tratarán de esconderse a causa de su enfermedad y también por causa de los delitos que cometen conexos a esta enfermedad sumado al abandono de la familia y la extrema pobreza por habitar la calle. 
El discurso de personas que propugnan por un derecho al consumo y una legalización de la droga tiene el distractor de presentarse como una minoría que utiliza los derechos derivados de las sentencias de la Corte Constitucional (C-221 de 1994 y C-491 de 2012). La realidad es que vienen a ser disertaciones que unen a personas que van en contra de un sistema de salud sin bases científicas para sustentar su «discurso»; sin sustento transdisciplinas, como lo aduce Cruz-Bermúdez (2013), igual pasa en las guerras interestatales, un bando se une contra otro bando para alcanzar un fin, se perjudican vidas y derechos humanos sin un objetivo. Las personas unidas en pro de los valores hacen discursos memorables que permiten acciones que elevan la condición del ser humano, como ocurrió en la marcha Selma; ${ }^{3}$ contrario a esto, Cultura G. (2012) relata como los jóvenes que se unen a la causa y la defensa de los partidos políticos que causan discriminación y afectación a intereses colectivos como es el caso del apoyo a las Juventudes del Partido Nacional Socialista.

El lenguaje de los derechos humanos y su interpretación pasa a ser otro inconveniente cuando el discurso va encaminado a todos los habitantes de un territorio de forma general, para lograr un consenso y una cohabitabilidad, pero vienen pequeños grupos que no se sienten identificados y que buscan asociarse con otros pares en búsqueda de justificaciones de sus actos. La comunicación de los derechos individuales es efectiva para todos y sirve como pretexto para defensa de intereses egoístas y pasa a convertirse en discurso sin contenido, cuando vienen a ser los conglomerados quienes

${ }^{3}$ Esta marcha fue iniciativa de un grupo de hombres negros liderados por el doctor Martin Luther King desde Selma (Alabama) hasta Montgomery (Alabama), para concientizar a los blancos acerca del respeto por los derechos de los negros, acabar sus actos de discriminación y permitir el derecho al voto frente a una política segregacionista. El recorrido fue de 87 kilómetros. los desean. Habermas (1989) advierte que la comunicación de los derechos colectivos que propugnan por los derechos individuales (como presupuesto de supervivencia) debe ser personal y reveladora, para que logre su efectividad, mediante significados que concienticen a cada ser humano sobre la importancia de sus acciones, para el beneficio propio y los demás.

El discurso «legalizador» de la droga es de doble vía: por una parte permite el consumo (dosis personal o de aprovisionamiento) pero por otra, castiga a quien la suministra, es decir, quien la consume debe ocultar al proveedor que favoreció la satisfacción de su derecho. El consumidor se convierte en un determinador del flagelo del tráfico y porte de estupefacientes como crimen que afecta la salud pública. Por tanto, en consideración al planteamiento de Arendt (2007), la acción del consumo de drogas, en un principio puede causar éxtasis y sentimientos de clímax en la persona, pero este acto (ausente de discurso) genera frustración a corto plazo en la persona que lo hace, y este sentir de derrota dominará de ahí en adelante sus demás acciones en las que utilizará el consumo como medio de escape frente a la realidad. Por tanto, el lenguaje debe ir encaminado en lograr que las acciones puedan convertirse en actividades productivas «dignas de confianza, tales como la fabricación, contemplación, cognición e incluso labor» (Arendt, 2007, p.211), porque acciones que no tengan este carácter (como el consumo de droga) son irrelevantes.

El discurso de los derechos humanos del siglo XXI debe ser divulgado para que sea efectivamente apropiado y acogido por las nuevas generaciones. Los enfoques morales y de derechos humanos deben estar ligados con la necesidad de supervivencia inspirados en la bioética para que se transmitan mediante metáforas que hagan reflexionar al ser humano. En el consumo de estupefa- 
cientes el discurso debe ir encaminado hacia la prevención de este y la importancia de la realización de los objetivos y propósitos de ese discurso como mecanismo de conservación de la especie y el desarrollo humano.

El ser humano sigue su proceso de auto constitución, para encontrar día a día su propósito; Morin (1999) afirma que la identidad de este siglo viene a ser de carácter planetario a fin de conservar lo humano y lo no humano, lo que implica partir del discurso, crear una identidad común en valores y evitar la autodestrucción del ser humano. Si los siglos XXI y Xx fueron neoliberales e individualistas, el actual es el siglo del lenguaje de los derechos colectivos en conexidad con los individuales. Los derechos sociales como la salud pública y el medioambiente afectan los derechos individuales de las generaciones futuras, y en este sentido el discurso jurisprudencial debe cambiar para ser biojurídico.

Arendt (2007) considera que la trama de las relaciones humanas está ligada a la fundamentación de las acciones como generadora de otras acciones, es decir, los seres humanos son fabricantes de acciones que serán transmitidas hacia otras personas por medio de voluntades, conflictos, hábitos y costumbres. Las acciones sin discurso (las irrelevantes) son mejor transmitidas que aquellas que conllevan un respeto por sí mismo y por el otro, situación que considera infortunada, porque las primeras producen deseos concupiscentes mientras que las segundas requieren virtud y disciplina. Un mensaje permisivo de una acción sin discurso (consumo de estupefacientes) es más fácil atenderlo que prevenirlo porque la enseñanza del pretexto es más fácil que el contexto.

\section{El sentido de vida del drogodependiente}

La importancia de la existencia del hombre radica en los dos eventos más importantes, su propia existencia y el descubrimiento del sentido de su existencia.

Twain, M. 2001

Díaz-Sarmiento, López-Lambraño, \& Roncallo (2017) consideran que la generación actual de jóvenes de este siglo están inmersa en un estancamiento propio de una identidad egoísta en la cual los padres no se preocupan por formar seres humanos con planes hacia un futuro. El interés no es trascender, solo disfrutar. El propósito inmediato de la gran mayoría es viajar por el mundo y encontrar la felicidad por medio del goce y el disfrute de las nuevas tecnologías. La juventud desea independencia, intimidad, desean durar todo el tiempo posible en las casas de sus papás, no desean procreary no son estables laboralmente y menos cuando se les ofrece un trabajo que implique el cumplimiento de un horario. La nueva cultura o generación no reconoce el valor de la labor, no le interesa a parecer en el ágora, en el escenario público.

Arendt (2007) describe las dos condiciones del hombre que hacen de él un ser con un sentido de producción más allá de cualquier acción y discurso: el homo faber y el homo laborans. El primero busca hacer el mundo más útil y hermoso, y el segundo la vida más fácil y duradera; sin embargo, se debe entender que sea cual sea la condición del ser humano, la realidad es un factor que no se puede negar. El problema es la concepción de este fenómeno, porque día tras día el ser humano busca su sentido de vida, para hacer parte de un mundo dinámico que exige vivir sin que importe el sufrimiento. La ausencia de una ética que implique pagar un alto precio de disciplina y algo de sufrimiento para alcanzar una meta no se puede formar seres humanos dispuestos 
a cambiar su entorno. Los que trascienden son aquellos que se adaptan a la realidad y se engranan en este círculo y proponen soluciones comunes a todos: esto es «el sentido común» (Arendt, 2007, p.205).

Un adicto al consumo de estupefacientes se convierte en un ser irrelevante, porque al adentrarse en el flagelo de la droga empieza a percibir la realidad de forma distorsionada, que según Arendt (2007) sería con falta de sentido común. El discurso en torno a la defensa del consumo de drogas se convierte en un sin sentido que busca justificar conductas que afectan la dignidad del ser humano y su desarrollo. Los grupos que buscan la unión de personas que han contribuido en algo con el mejoramiento de la existencia del hombre o el encuentro colectivo de víctimas de un flagelo buscan justicia restaurativa impulsados por un propósito y la existencia de intereses altruistas. Las asociaciones de adictos y consumidores de marihuana que buscan el derecho al consumo de estupefacientes, no son otra cosa que fundaciones ${ }^{4}$ que buscan mantener la vigencia de un instrumento que acaba poco a poco con la vida de los consumidores y afectan su entorno social, su estado de salud, y su dignidad.

El dilema que se plantea en relación con el hombre y su sentido está ligado al papel del individuo en una sociedad productiva, es decir, para que el hombre trascienda debe experimentar su inteligencia y ponerla al servicio de su comunidad. El siglo XXI es acelerado, la sociedad exige que los jóvenes a los 25 años obtengan un pregrado, un postgrado y un trabajo estable, los jóvenes al no lograrlo entran en un campo denominado «frustración», y esto se debe a la comercialización del estatus de «genio» (Arendt, 2007, p.235). Los jóvenes no saben discernir entre lo que es un oficio o un arte,

${ }^{4}$ Por ejemplo, la asociación Alacannabis, colectivo formado en España por casi un centenar de personas que defiende el uso de esta sustancia, para una finalidad lúdica. no tienen deseos de superación, se dejan influir por la sociedad de consumo y se adentran en el mundo del ocio y la adicción de las drogas como método de escape a la frustración al no llegar al estado de relevancia; por lo tanto, la condición del adicto es de total irrelevancia para la sociedad por perder su sentido ontológico y deontológico de la vida.

Arendt (2007) habla del verdadero «super hombre» de Nietzsche como aquel que transforma sus acciones en labores trascendentales ejercitando sus dones al servicio de la sociedad en la que vive, para convertirse en un genio o un literato imperturbable frente al odio y la humillación de quienes no han logrado alcanzar sus metas y esto lo alcanzan los literatos y los artistas ya que sus obras permanecen en el recuerdo de la sociedad.

Una dignidad para el adicto habitante de la calle conlleva, según Arendt (1996), potenciar las capacidades laborales del ser humano y en consonancia con la neurociencia se debe entrenar en las personas la memoria del trabajo y cultivar el pensamiento, la reflexión, la planificación y la toma de decisiones. La prevención de la vagancia y los vicios debe estar inmersa en la jurisprudencia; por tanto, se sugiere a los padres permitir que los menores contextualicen la realidad y que puedan madurar con mayor rapidez con cultura de trabajo y disciplina.

El pensamiento aristotélico en la jurisprudencia permitiría recuperar el lenguaje de la ética y la política en aspectos como la felicidad, la justicia, la virtud moral, cívica y política, la educación de los sentimientos, los cuestionamientos que forjan el carácter individual y colectivo a la altura de los principios alcanzados por una sociedad moral (González, 2007, p.91-92). El papel de esta filosofía es relevante en la configuración actual de las teorías éticas que han inspirado a lo largo de la historia la filosofía política y que han sido abandonadas por teorías utili- 
taristas y dialógicas que le han dado contenido nihilista a la dignidad.

Thiebaut (1992) confirma que los factores ontológicos y deontológicos del ser humano sirven para dar respuestas a las preguntas sobre la justicia y la elaboración de verdaderos sistemas pluralistas con fundamentos morales, a esto se suma Sampeiro, C., \& Barrachina (2007) que consideran que la biojurídica fundamenta y establece la pertinencia de las normas jurídicas legales o jurisprudenciales para adecuarlas a los valores de la bioética.

\section{Discusión}

Se confrontan los resultados obtenidos frente a los aspectos filosóficos esbozados por la Corte Constitucional, la biojurídica debe ser el puente para la unión de los derechos y la ética; por lo tanto, es necesario discutir acerca de lo estipulado en la jurisprudencia frente a lo que se considera el deber ser, hay que reconocer la tradición liberal, sin embargo, el propósito es sugerir un enfoque con tendencia al desarrollo humano.

Las sentencias C-221 de 1994 y el radicado 41760 de 2016 (en similar sentido) le otorgan relevancia a la libertad individual, por lo tanto, según esta providencia el Estado no es omnímodo y no debe entrometerse en las decisiones de las personas o los sujetos destinatarios porque al hacerlo viene a convertirse un Estado paternalista $y$ protector de sus ciudadanos y que no conoce lo conveniente para los adictos.

La crítica se enfoca en el tratamiento psiquiátrico para los drogadictos y lo hace ver como un modelo «represivo censurable» que trata a los drogodependientes como heterodoxos. La Corte cita irónicamente: «El hecho de drogarse no es una enfermedad involuntaria, es una manera totalmente deliberada de afrontar la dificultad de vivir, la enfermedad de vivir. Pero como no sabe curar la enfermedad de vivir, preferimos tratar al drogadicto» (Szasz, 1974, citada por Corte
Constitucional C-221, 1994), es decir, la Corte en primer lugar permite el consumo y en segundo término, cuestiona el tratamiento para estas personas ya que por su pobreza no podrán escoger el cómo curarse.

La sentencia en estudio le da una característica ilimitada al libre desarrollo de la personalidad, es decir, el ser humano debe «poder» elegir lo bueno, así como puede escoger lo malo; por lo tanto, las personas deben ser libres y autónomas para elegir su forma de vida mientras no exista interferencia con la vida de los otros. La providencia C-221 no comparte del todo la doctrina socrática que estipula que el único mal que aqueja al hombre es la ignorancia, porque se conoce la verdad, se conoce el bien; empero, su explicación tiene como fundamento que el conocimiento y la disposición a la verdad de la satisfacción hace parte de la esfera de la libre elección del ser humano. En este punto se debe diferir porque «la esencia de la verdad es la verdad de la esencia» (Heidegger, 2012, p.217). Trujillo (2019) considera que no es posible hacer que el ciudadano conozca un hecho que le hace daño como una forma de ejercer una libertad porque esto implica negar la realidad de las consecuencias.

La Corte Constitucional considera que el Estado debe respetar la libre elección de lo dañino para el hombre, porque el prohibir el consumo y tratarlo significa la manipulación de la conciencia del adicto, y lo justifica teniendo en cuenta que «el aglutinante social que mantiene unida a la sociedad liberal consiste en poco más que el consenso en cuanto a que lo esencial de la organización social estriba en dar a todos la posibilidad de crearse a sí mismos según sus capacidades» (Rorty, 1991, citada por Corte Constitucional C-221, 1994).

El Alto Tribunal critica el tratamiento médico para el drogodependiente, porque «los shocks eléctricos, los cortes quirúrgicos y los tratamientos químicos no educan, inducen 
conductas irresistibles (...)». Para la Corte Constitucional debe primar la educación y no el tratamiento, ya que la primera va dirigida a hombres libres mientras lo segundo a los animales. La Corte en parte tiene la razón: la educación se puede utilizar como medio eficaz de prevención; no obstante, cuando la persona pasa a ser adicta, su tratamiento debe ir acompañado de otras disciplinas que ayudan a la curación del adicto, tal como se ha demostrado en los índices de Undoc. Esta es la postura asumida hoy en día por el sistema jurídico, el cual observa la libertad como presupuesto de garantía de los demás derechos sin importar que las decisiones que adopte el ciudadano afecten su salud y su desarrollo de vida.

La interpretación del principio de dignidad por parte del magistrado ponente va ligado a la autonomía personal y al libre desarrollo de la personalidad; sin embargo, olvidó tener en cuenta los demás principios que rigen la bioética para salvaguardar un apotegma tan esencial como la dignidad humana. Para sustentar esta tesis, la Corte declaró inexequible (inaplicable) el artículo 87 de la Ley 30 de 1986 que estableció que las personas que resultasen «afectadas» por el consumo (adictas) serán enviadas a los establecimientos especializados de tratamiento para la adicción, porque según la ponencia, no se puede obligar a una persona a tratarse de una enfermedad, cuando no desea curarse porque se estaría vulnerando el artículo 16 de la Constitución Política. ${ }^{5}$ Este hecho resulta contradictorio, porque se reconoce una afectación al consumidor, por la drogodependencia, y esta patología debe ser tratada con urgencia, porque la población habitante de la calle crece cada día más.

${ }^{5}$ Artículo 16 de la Constitución Política: «Todas las personas tienen derecho al libre desarrollo de su personalidad sin más limitaciones que las que imponen los derechos de los demás y el orden jurídico».
La sentencia T-043 de 2015 contiene consideraciones filosóficas de la sentencia C-221 de 1994 en lo que respecto a la libertad individual y la autonomía de los habitantes de la calle, para ejercer actividades de mendicidad. La elaboración del concepto de dignidad por parte de esta clase de providencias ha hecho que a los habitantes de la calle no se les exija en obligaciones tal como se le hace al ciudadano común. En la sentencia se le ordenó al ejecutivo adoptar políticas públicas, para garantizar que la Ley 1641 de 2013 (Ley de los habitantes de la calle) se lleve a su ejecución; sin embargo, las consideraciones que buscan exponer las garantías y derechos de esta población justifican situaciones que contrarían el sentido para el cual el hombre existe, la superación de su ser.

Lo paradójico es que a diferencia de la Sentencia de constitucionalidad C-221 de 1994 se observa que en esta situación la Corte Constitucional garantizó el derecho a la salud de la ciudadana por medio de la tutela y ordena que un equipo interdisciplinar compuesto por un médico, un psicólogo y un trabajador social, diseñen un programa de atención integral para la afectada. El mensaje enviado por esta sentencia es diferente frente al respeto por un consumo fundado en la autonomía del adicto para que este tenga la libertad de escoger si se cura o no en razón a un Estado liberal y social que respeta la voluntad humana. La jurisprudencia analizada hace una evaluación del problema de salud pública que se está presentando a causa de la drogodependencia y las diversas enfermedades conexas para garantizarle el derecho a una persona que si desea salir de este flagelo conforme a una Ley que fue pensada para esta población.

El mensaje es esperanzador en cuanto a la necesidad de empezar a tratar médicamente al habitante de la calle adicto; sin embargo, las justificaciones filosóficas para sustentar actividades como la men- 
dicidad, la vagancia, y el poco valor que se otorga a los tratamientos médicos no se ajustan a una bioética principialista. La dignidad debe garantizarse en el desarrollo del hombre en su integridad y no tener en cuenta exclusivamente la autonomía para el desarrollo del ser como erradamente lo contempla la jurisprudencia colombiana. Este fenómeno se le conoce como bioética complaciente que ha sido trabajado por Serrano-Ruíz-Calderón, J.M. (2013) y corresponde a los factores inmorales e inhumanos que buscan ser justificados por medio del derecho a fin de satisfacer los deseos de un grupo de personas.

La providencia analiza cuatro puntos para dar respuesta al problema jurídico planteado en ella; empero, para el desarrollo del objetivo del presente artículo es necesario analizar solo dos aspectos: la atención en salud a los habitantes de la calle como factor de garantía para su desarrollo humano, y el flagelo de la drogadicción en la jurisprudencia constitucional. En primer lugar, el término «indigente» es referido a personas desamparadas que acostumbran a vivir de la mendicidad de las calles de Bogotá, que han llegado a esta situación por circunstancias asociadas a la drogadicción, a la pobreza, la exclusión social, entre otros. Valencia (2003) considera que los grupos clasistas y extremistas de derecha los Ilaman «desechables» y buscan su eliminación por medio de «limpiezas sociales» como forma repudiable de discriminación que vulnera el Derecho Internacional de los Derechos Humanos.

Se les ha asociado con «el vicio, la locura y la delincuencia» y según la sentencia, estas condiciones son un termómetro que mide qué tanto es vigente la expresión Estado social y democrático de derecho. Otra paradoja es que la decisión reconoce que los habitantes de la calle son seres humanos que tienen necesidades, un pasado y un futuro, es decir, cuentan con un propósito; sin embargo, asocia el concepto de propósito con una apología hacia la justificación de la mendicidad como presupuesto que garantiza la dignidad, la libertad y la igualdad material de los ciudadanos. El postulado lo fundamenta en la Sentencia C-106 de 1997 la cual eliminó todo tipo penal y contravención que castigaba a los mendigos, vagos y personas que fingieran enfermedad para lograr la conmiseración de los otros, por considerar estas leyes como "peligrosistas» propias de una escuela positiva del derecho penal la cual castigaba a las personas por lo que eran y no por lo que hacían.

La concepción positivista del derecho penal ha hecho que la desigualdad social tenga como consecuencia que a esta población se les considere como «personas que no tienen el derecho a tener derechos» (Uribe, 2003, p.308). Para Nussbaum (2007) esta situación de indiferencia y exclusión trae desigualdad e imposibilita el ejercicio de derechos básicos para el hombre, también, la injusticia no solo comprende el aspecto económico, sino que también se puede dar en el sexo, la casta, la raza, que combinados entre ellos traen consigo la denominada miseria. La sociedad los trata como seres inferiores, enfermos, estorbos, cuyo acceso a la igualdad material se imposibilita.

En esta sentencia, se distorsiona el sentido del ser humano en su desarrollo, porque la habitabilidad de la calle ha generado exclusión por parte de las dos instituciones más importantes dentro de una sociedad: El Estado y la familia; y la falta de interacción de esta población hace que se les termine su sentido de vida. El tratamiento histórico que se da a estas personas ha sido desigual a causa de su no posicionamiento al no cumplir el objetivo de una sociedad económica que va en un solo rumbo consumista y neoliberal. Sen (2010) estima que la calificación que se hace hacia este grupo no es objetiva y no tiene fundamento filosófico 
ya que la mirada hacia ellos por parte de la sociedad es indiferente.

Una ética aristotélica resalta la importancia del sentido de vida como fundamento del crecimiento y la existencia del ser humano y debe inmiscuirse en las sentencias y las políticas públicas y ser una verdadera biojurídica. Es desatinado por parte de la jurisprudencia mostrar la mendicidad y la vagancia como «valores» y denomina como «virtuosos» a estos oficios, porque según la Corte quienes los practican son dignos consigo mismo.

La sentencia T-043 de 2015 reconoce que la drogadicción severa es un problema de salud pública y una enfermedad que tiene consecuencias físicas graves y afecta la autodeterminación y la autonomía de quienes la padecen. El Alto Tribunal al estudiar las consecuencias de la adicción, el flagelo de la pobreza y la indigencia, comienza a apartarse de lo presupuestado por la C221 de 1994 al resaltar la importancia del tratamiento médico con perspectiva en derechos humanos con disponibilidad y accesibilidad, con valoración por parte de un equipo interdisciplinario, para integrar al drogodependiente a la sociedad, aunque este llamado debe hacerse reiteradamente y con más vehemencia.

Las dificultades que se presentan por la adopción de proyectos bioéticos incluidos en la jurisprudencia colombiana son diversos, porque según los críticos, entre ellos, Pence (1995), las sociedades en donde florecieron concepciones de «ética de la virtud», y el «deber-moral» no eran democráticas porque estas virtudes eran apreciadas para unos pocos. Sin embargo, para Nussbaum (1995) la meta de todo consenso real es la justicia, entonces, la prudencia y la virtud son los caminos para alcanzarla y con este significado se debe buscar que las sentencias tengan un fundamento más cercano al interés y la supremacía del ser humano en la búsqueda de su objetivo y su propósito conforme a una dignidad que se fortalece con la virtud. A los ciudadanos se les debe inculcar un sentido ontológico en su conocimiento de sí mismos (Heidegger, 2012) y ético u deontológico en su relación con los demás (Lévinas, 1996).

Se observa una Corte Constitucional que le da una interpretación errada al fin del Estado proteccionista porque no incentiva el trabajo, la cultura del ahorro, la inversión $y$ el esfuerzo en los menores, sino que al contrario incentiva la mendicidad y la vagancia. Estos valores éticos fundamentan la sociedad y permiten la supervivencia futura, además, el control como mecanismo de prevención porque según Foucault (2003) el hombre es amo y Dios de su destino y él mismo decide sus acciones conforme al sacrificio que deba hacer frente a otros.

\section{Conclusiones}

El sistema jurídico y su jurisprudencia deben modificar su discurso, no incentivan el desarrollo humano de los habitantes de la calle drogodependientes, por tal motivo, deben interpretar contextualmente la filosofía con el fin de transmitir por medio de sus fallos una disertación con bases epistemológicas acotadas por las demás ciencias. La biojurídica debe ser el puente para la unión de derechos y la ética.

La jurisprudencia transdisciplinar debe ser el primer motor del desarrollo humano para la erradicación de la pobreza, porque la ciencia al ser fuente de conocimiento, sirve para el desarrollo de nuevas tecnologías y plantea cada día mejores estrategias en procura de mejorar las condiciones de vida humana conforme a la realidad.

Los conceptos jurídicos deben ir de la mano de la biología, la genética molecular, la medicina, las ciencias humanas, la psicología, entre otros, a fin de establecer criterios más eficaces y óptimos que realcen la condición humana para que los fallos jurisprudenciales sean emitidos con mejor 
criterio. Por ejemplo, importante involucrar a la economía, Stiglitz (2016) propone darle un rostro humano a la legislación y al sistema jurídico para que miles de millones de personas salgan de la pobreza como primer paso para un desarrollo sostenible.

La conexión de la filosófica aristotélica con el acompañamiento multidisciplinario debe hacer que el habitante de la calle drogodependiente se convierta en un sujeto autónomo y fin en sí mismo, con la posibilidad de darse sus propias leyes a partir de un diálogo que establecezca con su ser y aquellos que lo rodean acerca de los bienes y las virtudes que le permiten llevar una vida digna. Según esta premisa se puede hablar de una completa dignidad para la persona, quien al ser un fin y tener capacidades arquitectónicas como la razón práctica y la afiliación, permitirán descubrir qué vida debe llevar y ser libre de situaciones que lo esclavicen como los vicios.

La relación existente entre lo bueno y lo justo dentro del ámbito de una filosofía moral es innegable. Nussbaum (1995) traza su filosofía política en la justicia social y la igualdad a partir de la concepción del ser humano y de lo que implica la buena vida humana, por esto, la urgencia por salvar la justicia implica que el Estado por medio de su legislación y jurisprudencia debe hacer que el ser humano busque y encuentre su sentido de vida, en el cual se favorece el pluralismo moral, según el respeto de unos mínimos relacionados con las capacidades humanas básicas.

La enseñanza de la ética por medio de la biojurídica es el instrumento efectivo de una sociedad ideal. El camino es denso, los hombres se comportan bien por temor a la norma y el castigo que emana de esta. La prohibición jurisprudencial del consumo de estupefacientes debe valorarse a partir de una enseñanza, en la parte justificadora de las providencias, de las consecuencias en la salud y la afectación a los derechos del consumo y sus efectos secundarios.
Una jurisprudencia en materia de consumo de estupefacientes debe garantizar las condiciones mínimas de educación y persuasión en el conglomerado del sentido de existencia, porque sin este propósito no será posible la efectividad de los derechos individuales en una sociedad prestacional. Se reconoce la tradición liberal de la jurisprudencia, empero, no debe dogmatizarse. Para tomar decisiones, la Dignidad debe ser el límite al ejercicio de las actuaciones que la afectan, se debe limitar hacia su protección y respeto; por lo tanto, se debe analizar el concepto autonomía a partir de un comunitarismo moderno.

La jurisprudencia de las altas cortes ha hecho énfasis en su discurso liberal que propende hacia la exclusión posterior del ser humano que lo llevan a la mala interpretación de los derechos, porque las consecuencias de la adicción de los habitantes de la calle hacen que los discursos en contra de los ellos sean vehementes a fin de limpiar «el mal»; por lo tanto, existen dos discursos que hacen daño al ser humano: el de la autonomía sin sentido de la Corte Constitucional y el discurso de la sociedad totalizadora que repugna la pobreza y promueve la exclusión.

\section{Referencias}

Amor P, J. (2005). Introducción a la Bioética. I, 1a, Madrid, PPC.

Arendt, H. (1996). Entre el pasado y el futuro. Ocho ejercicios sobre la reflexión política. Barcelona: Península.

Arendt, H. (2007). La condición humana, Introducción de manuel Cruz. Barcelona: Paidós.

Aristóteles, A. (1970). Ética a Nicómaco. Madrid: Paidós

Blumenberg, H.(2003). Trabajo sobre el mito. Madrid: Paidós

Carroll, S. (2017). El gran cuadro: Los orígenes de la vida, su sentido y el universo entero. Madrid: Pasado y Presente. 
Cruz-Bermúdez, N. (2013). Psicología, neurociencia y drogadicción en Puerto Rico: Implicaciones para la investigación interdisciplinaria. Revista Puertorriqueña de Psicología, 24(2), 46-59

Cultura G. (2012). ¿Cómo es el Nacional socialismo a la criolla? NeoNazismo en Colombia Recuperado de: http://nazismocolombia.blogspot.com.co/2012/04/ como-es-el-nacionalsocialismo-la.html, consultado el 03 de septiembre de 2017.

Díaz-Sarmiento, C., López-Lambraño, M., \& Roncallo-Lafont, L. (2017). Entendiendo las generaciones: una revisión del concepto, clasificación y características distintivas de los baby boomers, $\mathrm{X}$ y millennials. Clío América, 11(22), 188-204.

Engle, C. L. (1977). The need for a new medical model: a chanllenge for biomedicine. Science, 196, 129-136.

Everitt, B.J. \& Robbins, T.W. (2005). Neural systems of reinforcement for drug addiction: from actions to habits to compulsion. Nature Neuroscience, 8, 1481-1489

Falk, D. (2000). Primate Diversity. Tallahassee: W.W. Norton \& co Inc

Ferraris, M. (2000). Nietzsche y el nihilismo (Vol. 43). Madrid, Ediciones AKAL.

Foucault. M. (2003). Las palabras y las cosas. Una arqueología de las ciencias humanas. Traducción de Elsa Cecilia Frost. Buenos Aires, Siglo XXI.

Frankl, V. (1991). El hombre en busca de sentido. Con un prefacio de Cordon W. Allport. Barcelona, Herder.

Gaos, ]. (2016). Introducción a El sery el tiempo de Martin Heidegger. Bogotá, Fondo de Cultura Económica.

Conzález, E. (2007). Una lectura actualizada de la ética aristotélica. La mirada de Martha Nussbaum. Revista Quaderns de Filosofía i Ciencia. 37, 91, 92.

Gutiérrez \& Vila - Coro. (2007). Bioética y biojurídica. Medicina y ética. Revista Internacional de Bioética, Deontología y Ética Médica, 18(19), 53-70

Habermas, J. (1989). El discurso filosófico de la modernidad. Trad. M. Jiménez Redondo. Madrid: Taurus.

Heidegger, M., \& Girardot, R. G. (1970). Carta sobre el humanismo. Madrid: Taurus.
Heidegger, M. (2012). De la esencia de la verdad: sobre la parábola de la caverna y el Teeteto de Platón. Madrid: Herder Editorial.

Hyman, S. E. Malenka R. C. \& Nestler, E. J. (2006). Neural mechanisms of addiction: the role of reward-related learning and memory. Annual Review of Neuroscience, 29, 565-598.

Lévinas, E. (1977). Totalidad e infinito. Salamanca: Sígueme.

Lévinas, E. (1996). Entre nosotros. Madrid: Pre-textos.

Morin, E. (1999). Los siete saberes necesarios para la educación del futuro. Medellín: Santillana

Ministerio de Salud y Protección Social. (2016). Política de atención integral en salud. Recuperado de: https://www.minsalud.gov.co/sites/rid/Lists/BibliotecaDigital/RIDE/DE/modelo-pais-2016.pdf

Miralles, A. A. (2007). Bioética, bioderecho y biojurídica (Reflexiones desde la filosofía del derecho). Anuario de Filosofía del Derecho. (24), 63-84.

Nussbaum, M. (1995). La fragilidad del bien fortuna y la ética en la tragedia y filosofía griega. Madrid: Visor.

Nussbaum, M. (2007). Las fronteras de la justicia. Consideraciones sobre la exclusión. Barcelona: Paidós.

OMS. (2004). Neurociencia del consumo y dependencia de sustancias psicoactivas. Informe de la Organización Mundial de la Salud. Ginebra: OMS.

Oriol-Bosch, A. (2012). Resiliencia. Educación Médica, 15(2), 77-78.

Parsons, T. (1970) Apuntes sobre la teoría de la acción. Trad. María Rosa Virganó. Buenos Aires: Amorrortu.

Pence, C. (1995). La teoría de la virtud. En P. Singer, Compendio de ética. Madrid: Alianza Editorial.

Rorty, R. (1991). Contingencia, Ironía y Solidaridad. Buenos Aires: Paidós.

Royo-Isach J., Magrané, M. Blancafort F. \& Ferrer, ]. (2004). Drogas de síntesis: del uso al policonsumo. Algunos riesgos asociados y una propuesta de intervención terapéutica. Revista Atención Primaria, 33(4), 209-213

Santo Tomás, D. A. (2001). Suma teológica. Sao Paulo: Loyola, 1. 
Sampeiro, C., \& Barrachina (2007). Bioética y biojurídica. Medicina y Ética, 18, 53-70

Sen, A. (2010). La idea de la justicia. Bogotá D.C.: Taurus.

Serrano-Ruiz-Calderón, J. M. (2013). Sobre la injusticia de la eutanasia. El uso de la compasión como máscara moral. Referencia a nuevos documentos bioéticos europeos. Persona y Bioética, 17(2), 168186.

Stiglitz, ]. (2016). El malestar en la Clobalización. Bogotá D.C.: Debolsillo.

Szasz, T. S. (1974). The myth of mental illness: Foundations of a theory of personal conduct. New York: HarperPerennial.

Thiebaut, C. (1992). Neoaristotelismos contemporaneous. En V. Camps, O. Cuariglia y F. Salmerón, Concepciones de la ética. Madrid: Trotta.

Trujillo, E. (2019). Paradojas en la jurisprudencia frente al consumo de estupefacientes. Análisis a partir de la bioética. Pensamiento Americano, 12 (24) 130-145.

Twain, M. (2001). El príncipe y el mendigo. Madrid: Pehuén.

UNODC (2016), Encuesta mundial de drogas. Oficina de las Naciones Unidas contra la Droga y el Delito. [En línea]. [Fecha de consulta 13 de agosto de 2017]. Recuperado de: https://www.unodc.org/doc/ wdr2016/WDR_2016_ExSum_spa nish. pdf

Uribe, M. T. (2003). Esfera pública, acción política y ciudadanía. Una mirada desde Hannah Arendt. En L. y. Carrillo, Los clásicos de la filosofía política. Medellín: Universidad de Antioquia.

Valencia, H. (2003). Diccionario Espasa de Derechos Humanos. Bogotá D.C.: Planeta Colombiana S.A.

\section{Jurisprudencia}

Colombia. Corte Constitucional Sala Plena. (6 de marzo de 1997). Sentencia C-106.
M.P. Hernando Herrera Vergara. [En línea]. [Fecha de consulta 6 de septiembre de 2017]. Recuperado de: http:// www.corteconstitucional.gov.co/relatoria/2001/c-1064-01.htm

Colombia. Corte Constitucional Sala Plena. (5 de mayo de 1994). Sentencia C-221. M.P. Carlos Gaviria Díaz. [En línea]. [Fecha de consulta 10 de agosto de 2017]. Recuperado de: http://www.corteconstitucional.gov.co/relatoria/2001/c-1064-01.htm Colombia. Corte Constitucional Sala Plena. (4 de febrero de 2015). Sentencia T-043. M.P. Jorge Iván Palacio Palacio. [En línea]. [Fecha de consulta 16 de agosto de 2017]. Recuperado de: http:// www.corteconstitucional.gov.co/relatoria/2001/c-1064-01.htm

Colombia. Corte Suprema de Justicia. (09 de marzo de 2016). Sentencia radicado 41760 del. M.P. Eugenio Fernández Carlier. [En línea]. [17 de febrero de 2019]. Recuperado de: http://www.ramajudicial.gov.co/relatoria 01.htm

Colombia. Corte Suprema de Justicia. (28 de junio de 2012). Sentencia C-491 M.P. Luís Ernesto Várgas. [En línea]. [17 de febrero de 2019]. Recuperado de: http:// www.corteconstitucional.gov.co/relato$\mathrm{ria} / 2001 / \mathrm{c}-491-12 . \mathrm{htm}$

Colombia. Ministerio de Defensa Nacional (01 de octubre de 2018). Decreto 1844 de 2018. Por medio del cual se adiciona el capítulo 9 del título 8 de la parte 2 del libro 2 del Decreto 1070 de 2015. Bogotá, D. C.

\section{Leyes}

Colombia. Congreso de la República. (12 de julio de 2013). Ley 1641 por la cual se establecen los lineamientos para la formulación de la política pública social para los habitantes de la calle y se dictan otras disposiciones. Diario Oficial. Bogotá, D. C., 2013. N. ${ }^{\circ} 48.849$.

\section{Nota}

"El presente artículo de revisión es una síntesis de la investigación realizada para la tesis doctoral La Dignidad y la justicia para el drogodependiente habitante de la calle. Problemas biojurídicos de la legalización, como tesis aprobada en el programa de Doctorado en Bioética de la Universidad Militar Nueva Granada. 